\title{
Laser additive manufacturing of intermetallic alloys for high- temperature applications
}

\author{
Silja-Katharina Rittinghaus ${ }^{1}$, Janett Schmelzer ${ }^{2}$, Markus B. Wilms ${ }^{1}$, Manja Krüger ${ }^{3}$ \\ 1 Fraunhofer Institute for Laser Technology, Germany \\ 2 Otto-von-Guericke University Magdeburg, Germany \\ 3 Institute of Energy and Climate Research (IEK-2), Jülich, Germany
}

\begin{abstract}
Intermetallic alloys like e.g. Iron-Aluminides, Titanium-Aluminides or MolybdenumSilizides are prospective materials for high-temperature applications. For additive manufacturing (AM) intermetallic structural materials are particularly challenging due to their high melting points, oxygen susceptibility and low temperature brittleness. The feasibility of manufacturing intermetallic Mo-Si-B alloys with the laser additive manufacturing process of direct energy deposition (DED) is demonstrated and recent results in characterizing rapidly solidified material with respect to correlations between process, composition and microstructures are presented. The possibility to dope the material with Yttrium oxide $\left(\mathrm{Y}_{2} \mathrm{O}_{3}\right)$ for dispersion is successfully demonstrated. Current challenges, e.g. homogenous distribution of alloying elements and applicability are addressed.
\end{abstract}

\section{Keywords}

Mo-Si-B alloys, laser additive manufacturing, high-temperature mechanical properties, oxide dispersion strengthening

\section{Introduction}

Hard to manufacture but high performing intermetallic alloys provide dormant potential to be used in demanding environments like e.g. high temperature, high stress or oxidizing atmospheres. Currently, Ni-based alloys are state of the art for applications in aerospace and energy production markets. Mo-Si-B alloys are promising substituents. Generally, Molybdenum-alloys are not oxidation resistant, but with high contents of Silicon and Boron, the formed intermetallic phases allow the formation of a thin oxide protection layer on the material surface [1]. Especially near-eutectic compositions in the Mo-Si-B system show a good oxidation resistance in temperature ranges between 600 and $1300^{\circ} \mathrm{C}$ [2]. Both high temperature strength and creep performance emphasize these materials' significance as prospective structural material for e.g. turbine blades [3-7]. Reasons for the outstanding properties are the intermetallic phases $\mathrm{Mo}_{3} \mathrm{Si}$ and $\mathrm{Mo}_{5} \mathrm{SiB}_{2}$, which finely distribute in the Molybdenum solid solution $\left(\mathrm{Mo}_{\mathrm{ss}}\right.$ ) matrix phase, improving creep and oxidation resistance to a high extend. A homogenous phase distribution is crucial to gain the desired properties. In [1, 8], Mo-9Si-8B (at\%) containing about 50 vol \% of matrix a-Mo phase and 50 vol \% of $\mathrm{Mo}_{3} \mathrm{Si}$ and $\mathrm{Mo}_{5} \mathrm{SiB}_{2}$ provides a good balance of mechanical properties. The same alloy produced by casting shows a yield strength of $700 \mathrm{MPa}$ at $1200^{\circ} \mathrm{C}$ and a maximum compression strength of $750 \mathrm{MPa}$ and thus exceeds high temperature properties of state of the art Ni-based alloys [13]. The coarse microstructure and phase distribution are recognized as a 
limiting issue for the oxidation resistance. The high melting point of Mo-Si-B materials, dependent on the composition equal to or higher than $2000^{\circ} \mathrm{C}[2-5,9]$, causes the fabrication mainly by powdermetallurgical methods consisting of multiple steps. The possibility to produce fine grained and dense samples is given, but so far only on laboratory scale. $[2,6,8$, 10-14]

When the application of innovative materials is hindered by the limits of conventional manufacturing, additive manufacturing (AM) can thrive. Materials with high brittleness are challenging candidates for machinability of any kind. Additive production techniques like the powder-bed based Laser Powder Bed Fusion (LPBF) or he powder-nozzle based Direct Energy Deposition (DED, also known as Laser Metal Deposition LMD) provide unique possibilities: The high intensity of the laser beam enables rapid melting even of high melting materials, and the solidification can be used to specifically design desired microstructures, e.g. directed or fine grained. The near net shape manufacturing allows part production without any or at least reduced post subtractive processing. Crack formation can be prevented by the usage of adequate preheating systems. These possibilities to manufacture demanding materials are up to know only used to a very small extend. Nevertheless, the high melting points are challenging for additive manufacturing processes as well. Following [16, 17], the hightemperature resistant eutectic Mo-17,5Si-8B and alloys of very similar compositions are quite a suitable candidates for AM. Besides excellent mechanical properties, the melting point of approx. $2000^{\circ} \mathrm{C}$ is the lowest in the Mo-Si-B system when meeting the eutectic composition. The printability of near-eutectic Mo-Si-B compositions with DED and the resulting microstructures were presented in [18]. Dense Mo-13.5Si-7.5B samples were consolidated by DED from pre-alloyed gas atomized powders. The microstructure was found to consist of $\mathrm{Mo}_{s s}$ matrix with embedded binary $\mathrm{Mo}_{3} \mathrm{Si}-\mathrm{Mo}_{5} \mathrm{SiB}_{2}$ and ternary $\mathrm{Mo}_{s s}-\mathrm{Mo}_{3} \mathrm{Si}-\mathrm{Mo}_{5} \mathrm{SiB}_{2}$ regions. The present work is based on this very first study and contains results of printing Mo-16.5Si7.5B with DED. Aspects of the manufacturing process itself, microstructure characterization and creep properties are included.

Oxide dispersion strengthening (ODS) is known to increase the materials strength especially at high temperatures and improve creep behavior. The feasibility to apply ODS in additive manufacturing of $\mathrm{Fe}-, \mathrm{Ni}-$, Ti-based and $\mathrm{y}$-TiAl alloys and the positive effect on mechanical properties has been demonstrated for various material systems [19-24]. It leads to increased hardness and strength. Nevertheless, the effect in structural intermetallic materials for high temperature applications is still widely unexplored. In this work, we attempt to apply ODS to the DED process of Mo-Si-B.

\section{Materials and Experimental}

Gas atomized powder material produced by Nanoval GmbH \& Co. KG, Germany was used in the size of 45-90 $\mu \mathrm{m}$. The compositions determined by EDX of the two batches used in this study were Mo-16.5Si-7.5B and Mo-13.5Si-7.5B (at.-\%).

The DED process was performed using a machine with a 3 -axis gantry system. A $2 \mathrm{~kW}$ diode laser system was used as the laser beam source. The powder was fed through a coaxial powder feed nozzle. The beam diameter was set to $0.6 \mathrm{~mm}$. The parameters used in this study were a laser power of $70 \mathrm{~W}$, a scanning velocity of $500 \mathrm{~mm} / \mathrm{min}$ and a layer height of $0.15 \mathrm{~mm}$. The preheating temperature was approximately $600^{\circ} \mathrm{C}$, reached via an inductive preheating system. The movable coil mounted on a vertical access allowed constant conditions in the respective processing plane. Shielding to prevent oxidation was realized by use of an 
Argon filled gas chamber and oxygen contents $<100 \mathrm{ppm}$. An additional inert gas stream of $151 /$ min was chosen to additionally protect the melt pool locally.

Oxide dispersion strengthened samples were produced in the same manner using Mo-SiB-powder doped with nano-sized (approx. $45 \mathrm{~nm}$ ) $\mathrm{Y}_{2} \mathrm{O}_{3}$ particles (abcr $\mathrm{GmbH}$, Germany) via a shortened milling process in a planetary mill. . The milling procedure was performed in a planetary mill (Pulverisette 4 Classic line, Fritsch GmbH, Germany) with zirconia grinding bowls and yttrium stabilized zirconia (YSZ) grinding balls (diameter: $5 \mathrm{~mm}$ ). The process included three milling intervals of $20 \mathrm{~min}$ each followed by pausing for $10 \mathrm{~min}$ to cool down the powder material. The milling atmosphere was argon.

Image analysis of the DED microstructure was performed using a SEM LEO 1455 EP (Carl Zeiss AG, Germany). The relative density of specimens was determined by computeraided light microscopical analysis. EBSD phase analysis was performed at FZ Jülich by E. Wessel. Micro-hardness was tested as HV0.3 using a semi-automatic Vickers tester (LECO Instrumente $\mathrm{GmbH}$, Germany) with a test load of $300 \mathrm{~g}$ and a testing time of $20 \mathrm{~s}$. The test indentation distance was $0.5 \mathrm{~mm}$. Creep tests were performed with a Zwick Roell Z100 machine including a Maytec furnace in pure argon atmosphere at $1093^{\circ} \mathrm{C}$.

\section{Results}

\subsection{DED of Mo-Si-B}

Typical defects for LMD of intermetallics are cracking, ablation as a consequence of internal stresses and porosity. The brittleness of Mo-Si-B is high due to present $\mathrm{T}_{2}\left(\mathrm{Mo}_{5} \mathrm{SiB}_{2}\right)$ and $\mathrm{Mo}_{3} \mathrm{Si}$ phases at room temperature. Therefore, preheating and slow cooling rates are required after the process to prevent thermally induced cracking. The final deposition strategy elaborated includes bidirectional scanning and slow cooling by a stepwise reduction of the induction powder over several minutes. Nevertheless, all samples detach from the substrate during the cooling stage. The size of the produced samples is approx. $20 \mathrm{~mm}$ length, $4 \mathrm{~mm}$ width and $10 \mathrm{~mm}$ height (Fig. 1, A). Pore formation could not be suppressed completely, but significantly reduced by iterative adapting of the scanning strategy. The relative density determined by optical measurements in polished cross sections (Fig. 1, B) is $>98 \%$.

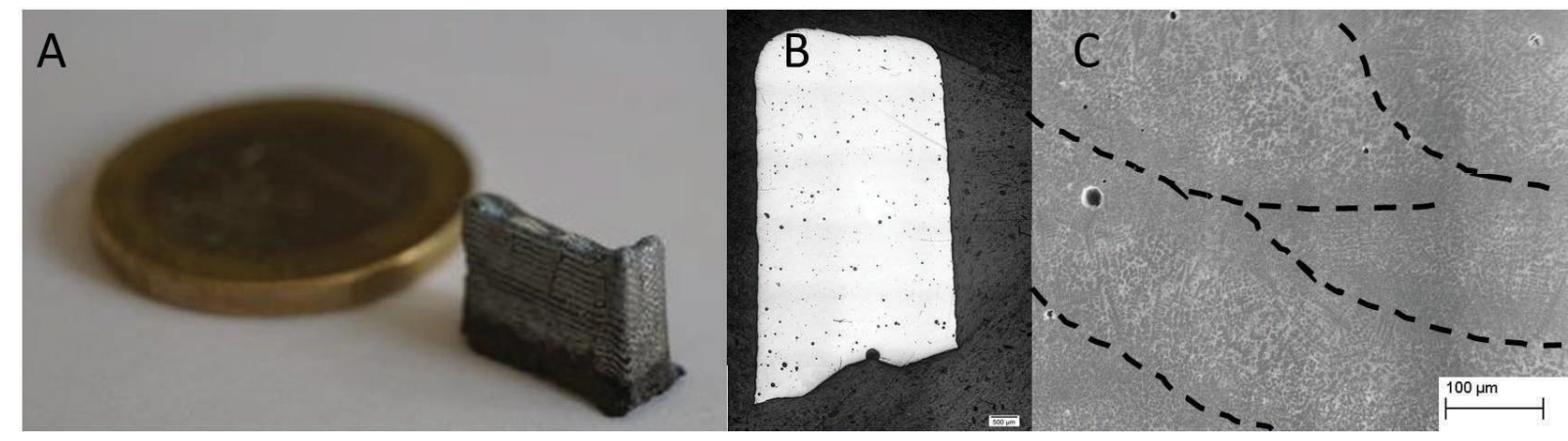

Fig. 1: Additively manufactured (DED) Mo-Si-B specimen: a) macro photograph of a sample b) LOM micrograph of the polished cross section c) LOM micrograph (etched) with drawn layers

SEM micrographs show homogeneous dendritic structure over the entire height with refined features in the solidification start region of each track (Fig. 1, C) triggered by different 
solidification speeds which are typical for AM processes. These regions are typically richer in Molybdenum (Moss). EBSD analysis reveals the phases $\mathrm{Mo}_{\mathrm{ss}}, \mathrm{Mo}_{3} \mathrm{Si}$ and $\mathrm{T}_{2}$ (Fig. 2). While $\mathrm{T}_{2}$ and $\mathrm{Mo}_{3} \mathrm{Si}$ are known to improve hardness, creep resistance and oxidation resistance the $\mathrm{Moss}_{\text {ss }}$ phase increases the room temperature toughness.

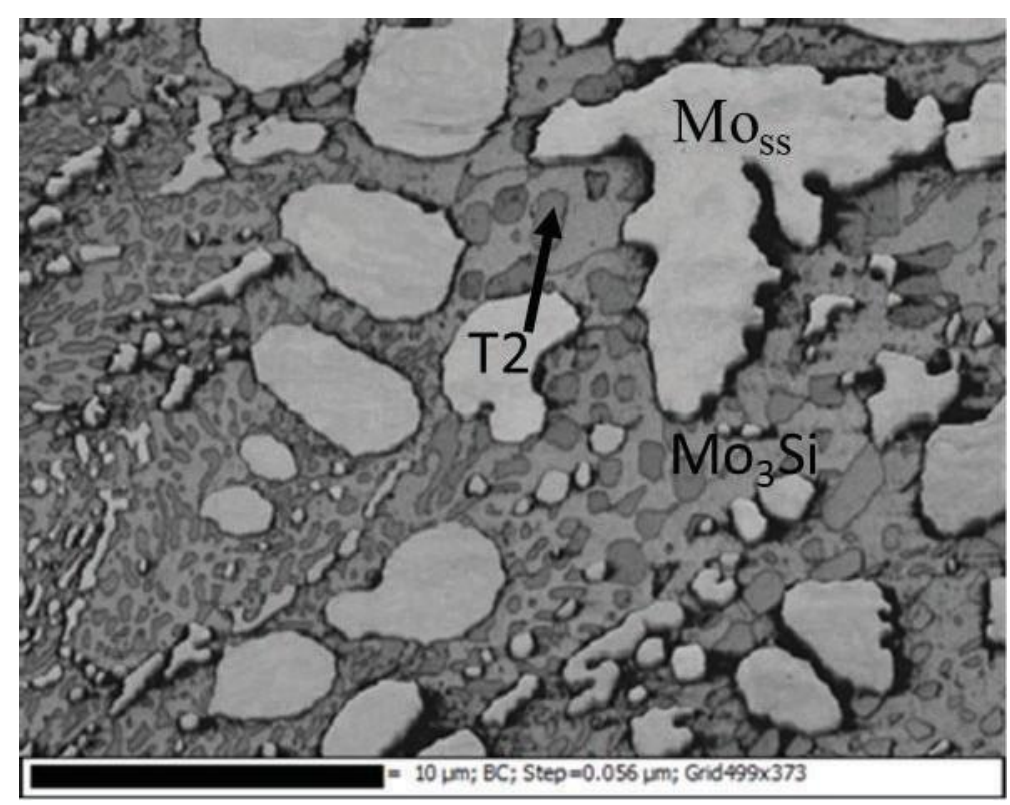

Fig. 2: EBSD of Mo-Si-B AM sample having a three-phase microstructure

Hardness measurements result in values of 1300-1400 HV0.3, which is in the expected range of the material $[5,19]$.

\subsection{Creep behaviour of DED manufactured Mo-16.5Si-7.5B}

A deeper insight into the mechanical behaviour of the DED Mo-Si-B alloy is given by tests of the creep rate of the material. The creep properties of the DED Mo-16.5Si-7.5B (tested in as-built conditions) are presented in Fig. 3. 


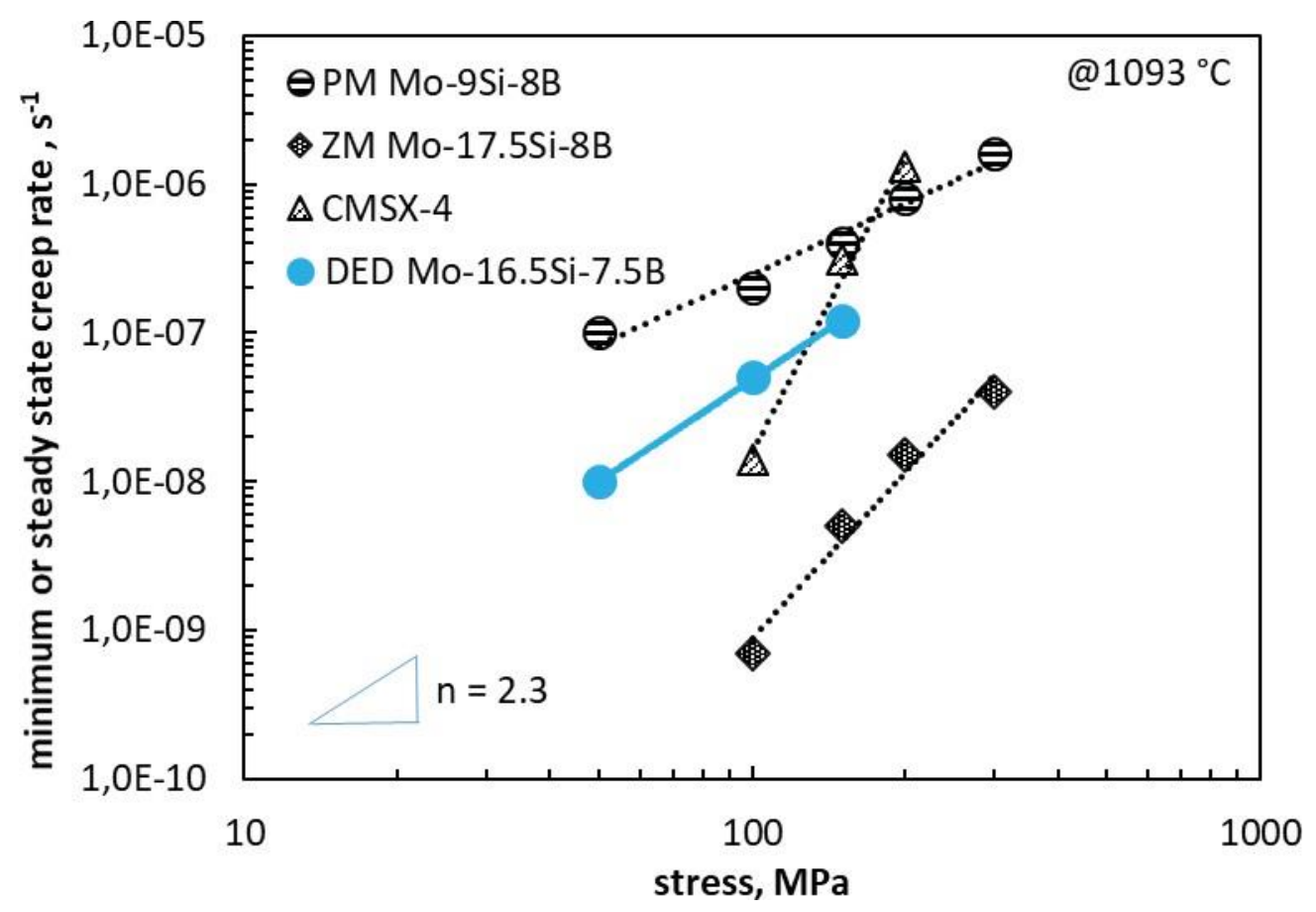

Fig. 3: Creep properties of the DED Mo-16.5Si-7.5 alloy at compared to other Mo-Si-B alloys having a three-phase microstructure and state-of-the-art CMSX-4.

The alloy shows a creep behavior located between a powder metallurgy (PM) Mo-9Si$8 \mathrm{~B}$ alloy, providing a microstructure of intermetallic $\mathrm{Mo}_{3} \mathrm{Si}$ and $\mathrm{Mo}_{5} \mathrm{SiB}_{2}$ phases which are embedded in a continuous $\mathrm{Mo}_{\mathrm{ss}}$ network $\left(\mathrm{Mo}_{\mathrm{ss}}>50 \%\right)$ [13], and the chemically very similar zone-molten (ZM) Mo-17.5Si-8B alloy. The chemical similarity of both alloys (DED Mo16.5Si-7.5B, ZM Mo-17.5Si-8B) leads to comparable phase distributions, with microstructures consisting of more than $50 \%$ of intermetallic phases $\left(\mathrm{Mo}_{3} \mathrm{Si}\right.$ and $\left.\mathrm{Mo}_{5} \mathrm{SiB}_{2}\right)$ due to the higher content of Si and B. A difference can be found in the grain size of the alloys, where the creep behavior is improved due to the coarser grained microstructure in the $\mathrm{ZM}$ Mo-17.5Si-8B alloy [17]. On the contrary, the higher proportion of Moss phase in the PM Mo9Si-8B lowers the creep resistance in comparison to the DED Mo-16.5Si-7.5B and ZM Mo17.5Si-8B alloy, since the $\mathrm{Moss}_{\text {ss }}$ phase provides the weakest creep strength of the three phases $\left(\mathrm{Mo}_{\mathrm{ss}}, \mathrm{Mo}_{3} \mathrm{Si}, \mathrm{Mo}_{5} \mathrm{SiB}_{2}\right)$ [25]. Relative to DED Mo-16.5Si-7.5B the creep response of the CMSX-4 alloy can be found in the same order of magnitude. The creep behavior of the DED manufactured Mo-16.5Si-7.5 alloy can be classified as competitive compared to other Mo-SiB alloys having a three-phase microstructure and the single-crystalline Ni-based superalloy CMSX-4.

\subsection{Oxide dispersion strengthening of DED manufactured Mo-13.5Si-7.5B}

In Fig. 4 A-B, the successful attempt to dope DED Mo-13.5Si-7.5B (composition determined by EDX) with $\mathrm{Y}_{2} \mathrm{O}_{3}$ is presented. The sample is free of cracks after the build-up. Nevertheless, by reasons of mechanical preparation cracking occurs afterwards, visible in the cross section (Fig. 4, B). The sample shows an identical grain structure with and without dispersed oxide particles. 


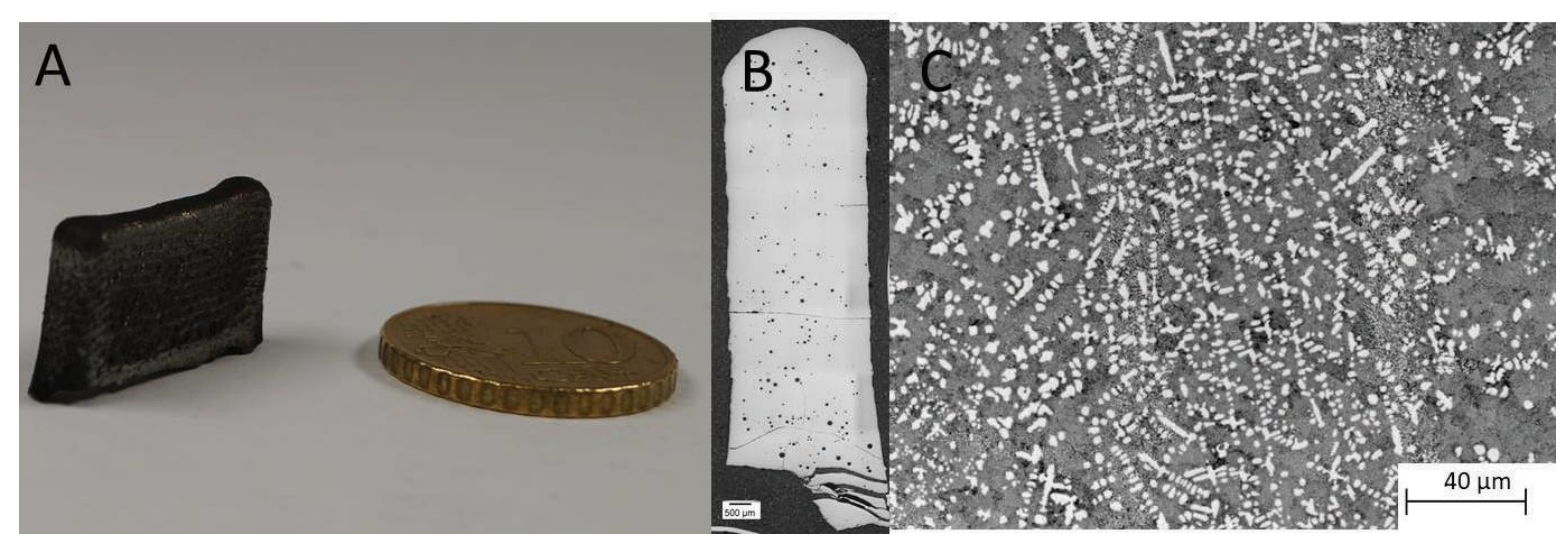

Fig. 4: Additively manufactured (DED), $\mathrm{Y}_{2} \mathrm{O}_{3}$-doped Mo-Si-B specimen: a) macro photograph of a sample b) cross section c) LOM micrograph

For comparison reasons, one reference sample without additional particles was produced out of the same batch (Fig. 5, B). SEM reveals finely dispersed $\mathrm{Y}_{2} \mathrm{O}_{3}$-particles (white spots) in the matrix phase of the doped sample (Fig. 5, A). The size of the particles is up to $500 \mathrm{~nm}$. The distribution however is not homogeneous. Clustered regions are visible as well as individual particles, following no obvious rule of accumulation. Nevertheless, they seem to segregate at phase boundaries, which has to be characterized in depth by EBSD measurements.

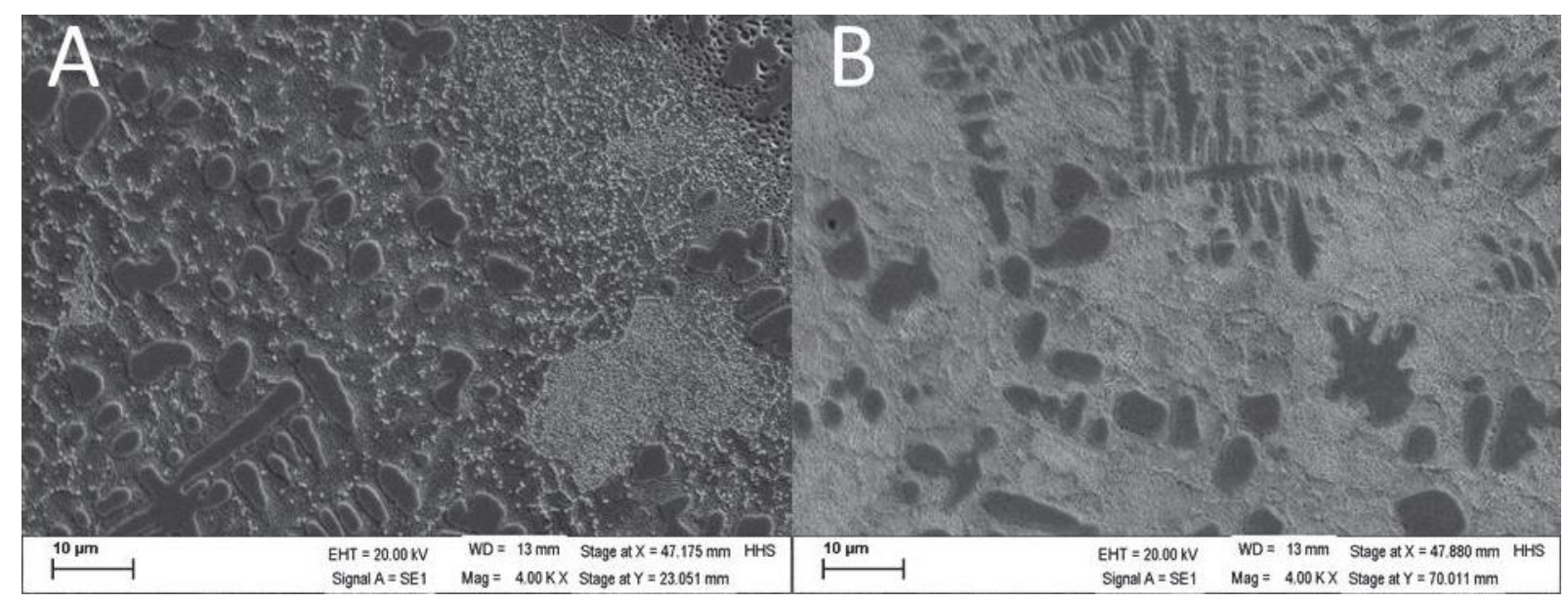

Fig. 5: Additively manufactured (DED) Mo-Si-B specimen: SEM micrographs A)

$\mathrm{Y}_{2} \mathrm{O}_{3}$-doped B) non-doped

When testing the samples against each other, the hardness is measured to be $1370 \pm 100$ HV0.3 compared to $1330 \pm 60 \mathrm{HV} 0.3$ in the non-doped sample. Therefore, no significant increase in hardness is found. Most likely the hardness induced by the intermetallic phases which predominate the microstructure is already so high, that under consideration of measurement deviations the additional gain is unrecognizable. Further investigations will include detailed analysis of the distribution of the particles and determination of creep behaviour in comparison with non-doped Mo-Si-B. 


\section{Summary and Conclusions}

In this work, the feasibility to build crack free bulk DED-samples with a high density out of the intermetallic Mo-16.5Si-7.5B alloy is demonstrated. Bulk crack free samples can be built out of Mo-16.5Si-7.5B gas atomized powder. The density is in the range of 98-99\%. The microstructure consists of the expected phases $\mathrm{Mo}_{\mathrm{ss}}, \mathrm{Mo}_{3} \mathrm{Si}$ and $\mathrm{T}_{2}$ with more than $50 \%$ intermetallic phase fraction. Furthermore, in accordance with literature and observed microstructure, the creep behaviour was tested to be in the range of a state of the art Ni-based super alloy. Oxide dispersion strengthening in order to increase the creep resistance was tested successfully. A first trial to dope Mo-13.5Si-7.5B with Yttrium-oxides was successfully performed, however leading to irregular distribution. Therefore further process adjustments, as well as creep tests of the material, are part of current research.

\section{Acknowledgements}

This research was partially funded by the Federal Ministry of Education and Research (BMBF), grant no. 03XP0094. We would like to thank our partners in the project and especially E. Wessel (FZ Juelich) and H. Horn-Solle (Fraunhofer ILT) for their analytical support.

\section{References}

[1] M. Krüger, P. Jain, S. Kumar, M. Heilmaier, Correlation between microstructure and properties of fine grained $\mathrm{Mo}-\mathrm{Mo}_{3} \mathrm{Si}-\mathrm{Mo}_{5} \mathrm{SiB}_{2}$ alloys, Intermetallics (2014, vol. 48), p. 10

[2] V. Supatarawanich, D.R. Johnson, C.T. Liu, Effects of microstructure on the oxidation behavior of multiphase Mo-Si-B alloys, Mater. Sci. Eng. (2003, vol. A 344), p. 328339.

[3] W.O. Soboyejo, T.S. Srivatsan, Advanced Structural Materials: Properties, Design Optimization, and Applications, CRC Press, Boca Raton, 2006.

[4] G. Hasemann, D. Kaplunenko, I. Bogomol, M. Krüger, Near-Eutectic Ternary Mo-SiB Alloys: Microstructures and Creep Properties, JOM 68 (11) (2016) 2847-2853.

[5] G. Hasemann, Microstructure and Properties of Near-Eutectic Mo-Si-B Alloys for High Temperature Applications, Doctoral Thesis Otto-von-Guericke-University, Magdeburg, 2017.

[6] A.P. Alur, N. Chollacoop, K.S. Kumar, Creep effects on crack growth in a Mo-Si-B alloy, Acta Mater. 55 (3) (2007) 961-973.

[7] Gibson, I., Rosen, D. W., and Stucker, B., Additive Manufacturing Technologies: 3D Printing, Rapid Prototyping, and Direct Digital manufacturing, 2nd., Springer, New York, (2015), pp. 1-498.

[8] M. Krüger, S. Franz, H. Saage, M. Heilmaier, J.H. Schneibel, P. Jéhanno, M. Böning, H. Kestler, Mechanically alloyed Mo-Si-B alloys with a continuous a-Mo matrix and improved mechanical properties, Intermetallics, 2008, vol. 16, pp. 933-941.

[9] M. Wanga, R. Lia, T. Yuana, C. Chena, M. Zhanga, Q. Wengc, J. Yuan, Int. J. Refract. Met. Hard Mater. 70 (2018) 9-18.

[1O] J.H. Schneibel, M.J. Kramer, D.S. Easton, A Mo-Si-B intermetallic alloy with a 
continuous a-Mo matrix, Scr. Mater. 46 (2002) 217-221.

[11] A. Yamauchi, K. Yoshimi, K. Kurokawa, S. Hanada, Synthesis of Mo-Si-B in situ composites by mechanical alloying, J. Alloys Compd. 434 - 435 (2007).

[12] Jéhanno, P., Heilmaier, M., Kestler, H., Böning, M., Venskutonis, A., Bewlay, B., et al., Assessment of a powder metallurgical processing route for refractory metal silicide alloys, Metal Mater. Trans. A, 2005, vol. 36, pp. 515-523.

[13] R. A. Gaisin, V. M. Imayev, R. A. Shaimardanov, R. M. Imayev, Structure and properties of Mo-9Si-8B alloy fabricated by casting, Inorganic Materials: Applied Research (2017, vol.8 (5)), p. 750-754 |

[14] Alur, A.P., Chollacoop, N., and Kumar, K.S., Hightemperature compression behavior of Mo-Si-B alloys, Acta Mater., 2004, vol. 52, pp. 5571-5587.

[15] K. Yoshimi, S.-H. Ha, K. Maruyama, K., R. Tu, T. Goto, Microstructural evolution of Mo-Si-B ternary alloys through heat treatment at $1800^{\circ} \mathrm{C}$, Adv. Mater. Res., 2011, vol. 278, pp. 527-532.

[16] M. Krüger, D. Schliephake, P. Jain, S. Kumar, G. Schumacher, M. Heilmaier, M.: JOM 65 (2013) 301

[17] G. Hasemann, I. Bogomol, D. Schliephake, P.I. Loboda, M. Krüger, Microstructure and creep properties of a near-eutectic directionally solidified multiphase Mo-Si-B alloy, Intermetallics (2014, vol. 48) p. 28-33

[18] J. Schmelzer, S.-K. Rittinghaus, A. Weisheit, M. Stobik, J. Paulus, K. Gruber, E. Wessel, C. Heinze, M. Krüger, Printability of gas atomized Mo-Si-B powders by laser metal deposition, International Journal of Refractory Metals \& Hard Materials (2019, vol. 78) p. 123-126

[19] T. Boegelein, S. N. Dryepondt, A. Pandey, K. Dawson, G. J. Tatlock. Mechanical response and deformation mechanisms of ferritic oxide dispersion strengthened steel structures produced by selective laser melting. Acta Materialia (2015, vol. 87) p. 201215

[20] A. B. Spierings, T. Bauer, K. Dawson, A. Colella, K. Wegener. Processing ODS modified IN625 using selective laser melting. Proc. 25th Ann Int.Symp. Solid Freeform Fabrication, Austin (2015)

[21] M. B. Wilms, R. Streubel, F. Frömel, A. Weisheit, J. Tenkamp, F. Walther, S. Barcikowski, J. H. Schleifenbaum, B. Gökce. Laser additive manufacturing of oxide dispersion strengthened steels using laser-generated nanoparticle-metal composite powders. Proc. CIRP (2018, vol. 74) p. 196-200

[22] D. Gu, H. Wang, G. Zhang. Selective Laser Melting Additive Manufacturing of TiBased Nanocomposites: The Role of Nanopowder. Metall and Mat Trans A (2014, vol. 45(1)) p. 464-76

[23] C. Kenel, G. Dasrgyri, T. Bauer, A. Colella, A. B. Spierings, C. Leinenbach, K. Wegener. Selective laser melting of an oxide dispersion strengthened (ODS) y-TiAl alloy towards production of complex structures. Mater. \&. Design (2017, vol.134) p. $81-90$

[24] S.-K. Rittinghaus, M. B. Wilms. Oxide dispersion strengthening of y-TiAl by Laser Additive Manufacturing. Journal of Alloys and Compounds (2019 vol.804) p. 457-460

[25] P. Jain, K.S. Kumar, Tensile creep of Mo-Si-B alloys, Acta Materialia (2010 vol. 58) p. 2124-2142. 